\title{
$P$-wave velocity structure in the northern part of the central Japan Basin, Japan Sea with ocean bottom seismometers and airguns
}

\author{
Takeshi Sato ${ }^{1,2}$, Masanao Shinohara ${ }^{3}$, Boris Y. Karp ${ }^{4}$, Ruslan G. Kulinich ${ }^{4}$, and Nobuhiro Isezaki ${ }^{5}$ \\ ${ }^{1}$ Graduate School of Science and Technology, Chiba University, 1-33 Yayoi-cho, Inage-ku, Chiba 263-8522, Japan \\ ${ }^{2}$ Deep Sea Research Department, Japan Agency for Marine-Earth Science and Technology (JAMSTEC), \\ 2-15 Natsushima-cho, Yokosuka 237-0061, Japan \\ ${ }^{3}$ Earthquake Research Institute, University of Tokyo, 1-1-1 Yayoi, Bunkyo-ku, Tokyo 113-0032, Japan \\ ${ }^{4}$ Pacific Oceanological Institute, Far Eastern Branch of Russian Academy of Science, 43, Baltiyaskaya Street, Vladivostok, 690041, Russia \\ ${ }^{5}$ Faculty of Science, Chiba University, 1-33 Yayoi-cho, Inage-ku, Chiba 263-8522, Japan
}

(Received March 24, 2003; Revised November 4, 2003; Accepted March 31, 2004)

In 1996, an airgun-ocean bottom seismometer survey was carried out in the northern part of the central Japan Basin. The crustal thickness in the central part is about $9 \mathrm{~km}$, including a sedimentary layer with thickness of 1.5 $\mathrm{km}$, and increases eastward. The obtained crustal structure is slightly different from those of typical ocean basins. The thickness and velocity of less than $6.5 \mathrm{~km} / \mathrm{s}$ in the upper part of the crust do not correspond to that of a typical oceanic crust and the clear linear geomagnetic anomaly around this survey line has been unconfirmed. Although, this crust could be interpreted to be either anomalous thick oceanic crust formed at spreading centers influenced by a mantle plume or thinned continental crust at ocean-continental boundaries in passive margins, we prefer the latter as a conclusion, that is, it may be formed by thinning of a continental crust rather than by the melt of mantle plumes during the opening of the Japan Sea. In addition, the difference of the crustal structures in the study area and the northeastern Japan Basin where the crust is typical oceanic, indicates that the process of crustal formation may differ in the northern part of the central Japan Basin from in the northeastern Japan Basin.

Key words: $P$-wave velocity structure, Japan Basin, Japan Sea, ocean bottom seismometer.

\section{Introduction}

Japan Sea, which is a back-arc basin in the northwestern Pacific, is located between Asian continent and Japanese islands. It comprises the Japan Basin in the north and northwest, the Yamato Basin in the southeast, and the Tsushima Basin in the southwest. At the junction of these basins, the Yamato Rise is located and forms a topographic high (Fig. 1).

To understand the formation of the Japan Sea, many geophysical and geological surveys have been conducted in the Sea. From ocean bottom seismometers (OBSs) investigations, different types of crust have been found in the Japan Sea. The northeastern Japan Basin shows an oceanic crustal velocity structure with a total thickness of about $8.5 \mathrm{~km}$ including a 2-km-thick sedimentary layer (Hirata et al., 1992). The crust of the Yamato Basin, which is about 14-16 km thick including a 1-km-thick sedimentary layer, is two times thicker than that of a typical oceanic crust (e.g., Hirata et al., 1989; Nishizawa and Asada, 1999; Nishisaka et al., 2001), thus the northern Yamato Bain could be formed by extension of the island arc crust (Nishizawa and Asada, 1999), however, the southern Yamato Basin was interpreted the crust affected by volcanism during the late stage of spreading ( $\mathrm{Hi}-$ rata et al., 1989). The crustal thickness of the Tsushima Basin is similar to that of the Yamato Basin (Kurashimo et al., 1996; Kim et al., 1998). The Kita-Oki Bank, which is

Copy right(c) The Society of Geomagnetism and Earth, Planetary and Space Sciences (SGEPSS); The Seismological Society of Japan; The Volcanological Society of Japan; The Geodetic Society of Japan; The Japanese Society for Planetary Sciences; TERRAPUB. a southern extension of the Yamato Rise, has a thick 6-km/s layer, suggesting the Bank to be also a stretched continental crust fragment (Kurashimo et al., 1996). The Kita-Yamato Trough has a crustal thickness of about $12 \mathrm{~km}$ including a 1.5 -km-thick sedimentary layer, but does not have a high velocity layer $(V p>7.1 \mathrm{~km} / \mathrm{s})$ in the lower part of the lower crust, suggesting the Trough to be a rifted/stretched continental crust (Sato et al., 2001). In the Yamato Rise area, OBS survey has not been conducted, however, previous studies show that the shallow part of the crust is of the continental type (Murauchi, 1972; Ludwig et al., 1975) and the depth of Moho is suggested to be about $22.5 \mathrm{~km}$ from gravity modeling (Yoshii, 1972).

The Japan Sea is now one of the most well studied backarc basins in the world in terms of crustal structure. However, to reconstruct and understand the opening process of the Japan Sea that possesses different types of crustal structures, it is necessary to clarify more detailed crustal structure where information of seismic velocity structure is still missing. In particular, the central Japan Basin is inferred to correspond to the tip of a rift propagation, an opening process of the Japan Sea proposed by Tamaki et al. (1992). However, no modern seismic experiment has been conducted in this area. The purpose of this study is to present the crustal structure of the northern part of the central Japan Basin, and to discuss its formation process. 


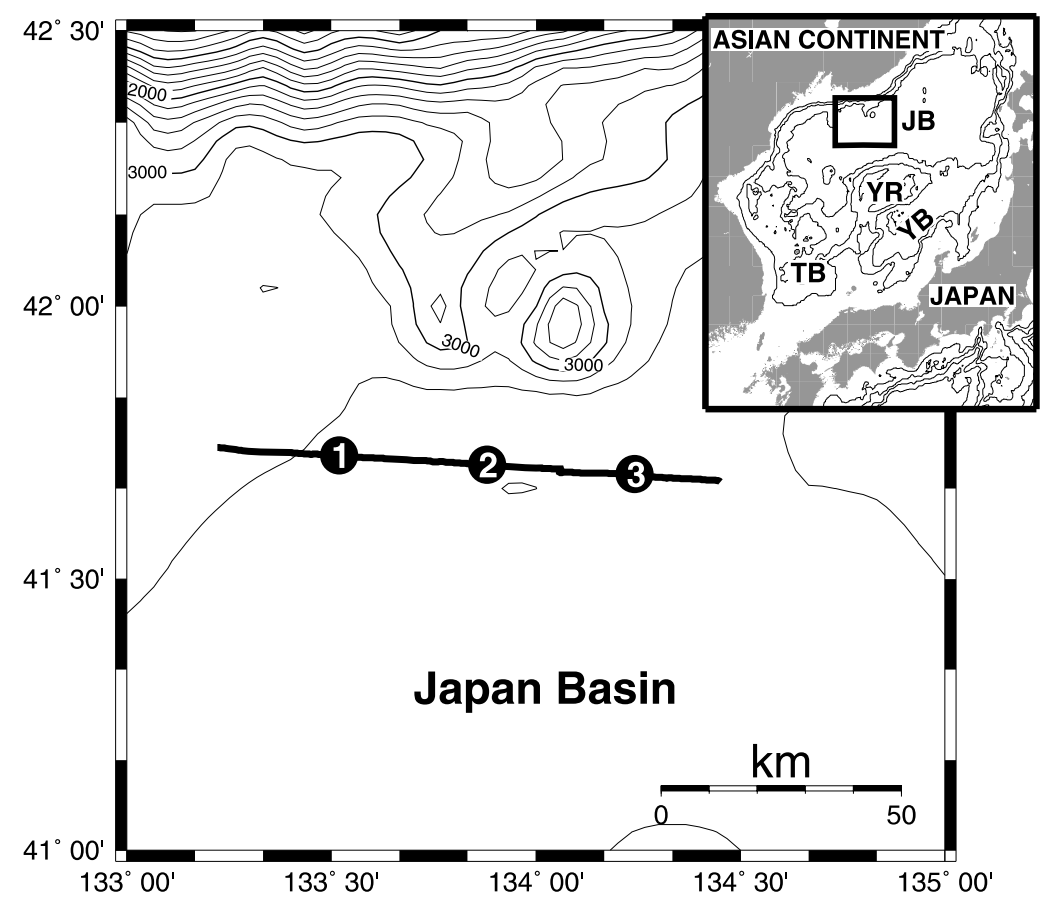

Fig. 1. Map showing the location of seismic experiment in the northern part of the central Japan Basin. Solid Line shows the seismic refraction/reflection survey line. Positions of deployed ocean bottom seismometers (OBSs) are denoted by solid circles and numerals indicate station number. Bathymetric contour interval is $200 \mathrm{~m}$. Inset shows topographic map of the Japan Sea showing JB (Japan Basin), YB (Yamato Basin), TB (Tsushima Basin) and YR (Yamato Rise). Bathymetric contour interval is $1000 \mathrm{~m}$.

\section{Experiment}

In July 1996, a seismic refraction and reflection survey was conducted in the northern part of the central Japan Basin off Vladivostok, Russia. This survey was a joint expedition of the Chiba University and Pacific Oceanological Institute, Far Eastern Branch of Russian Academy of Science (POI). Three OBSs were deployed with $30 \mathrm{~km}$ interval along a 103-km-long profile in an east-west direction (Fig. 1). The OBS used in this experiment was designed by Shinohara et al. (1993). Two 20-liter airguns towed from the R/V Professor Gagarinsky, POI were fired as controlled seismic sources along the line. The shot interval was $120 \mathrm{~s}$, which corresponds to approximately $300 \mathrm{~m}$ in horizontal distance, to enable a very high lateral resolution of the crustal velocity structure. The reflection data was recorded by a singlechannel hydrophone streamer towed from the R/V Professor Gagarinsky. The ship positions during the OBS deployment, recovery and airgun shooting were determined by the Global Positioning System (GPS).

\section{Data and Analysis}

The OBSs recorded high quality seismic signals (high signal-to-noise ratio) along the entire profile (Figs. 2(a)4(a)). The record section of OBS1 has first phases with an apparent velocity of about $8 \mathrm{~km} / \mathrm{s}$, which are interpreted to refract from the uppermost mantle, at offset distance beyond $40 \mathrm{~km}$ to the east of the OBS (Fig. 2(a)). On OBS2 record section, first arrivals with a velocity of about $8 \mathrm{~km} / \mathrm{s}$ appear at offset distance beyond $40 \mathrm{~km}$ to the west of the OBS but was not observed in the east side (Fig. 3(a)). On OBS3 record section, the phases, which has an apparent velocity of about $8 \mathrm{~km} / \mathrm{s}$, appear at offset distance beyond $45 \mathrm{~km}$ to the west of the OBS (Fig. 4(a)). These suggest that the crustal thickness increases eastward.

To obtain the shallow structure of the sedimentary layer and make the initial model for 2-D modeling, we used the reflection seismic data (Fig. 5) and applied direct $\tau-p$ mapping and $\tau$-sum inversion to refraction data to derive onedimensional models (Diebold and Stoffa, 1981; Shinohara et al., 1994). There is an excellent correlation the boundaries between the result for this analysis and the reflection seismic data at least down to the acoustic basement layer except the west side of OBS3 (Fig. 5). The geometry and $P$-wave velocities of the sedimentary layer are initially constrained by the results of this analysis. An initial model using the results of these one-dimensional models is constructed. Then, the ray tracing method was employed to calculate the travel times in the two-dimensionally varying velocity model (Červený et al., 1977; Hirata and Shinjo, 1986). Velocity boundaries in the upper part of the crust were set when the peak or change of the trajectory existed in the $\tau-p$ domain of the OBS record and the triplications on the OBS records existed (Fig. 6(a)). When no triplication existed and the apparent velocity of the refracted wave changed gradually, the changes were explained using a velocity gradient in the lower part of the crust. For the travel time fitting, we regard a model as a satisfactory one when differences between computed and observed travel times were less than maximum 0.1 $\mathrm{s}$ and computed and observed amplitudes were generally explained reasonably well (Figs. 2-4).

\section{Results}

In Fig. 7, we present the $P$-wave velocity model obtained by the experiment. Our model indicates that the sedimen- 


\section{OBS1}

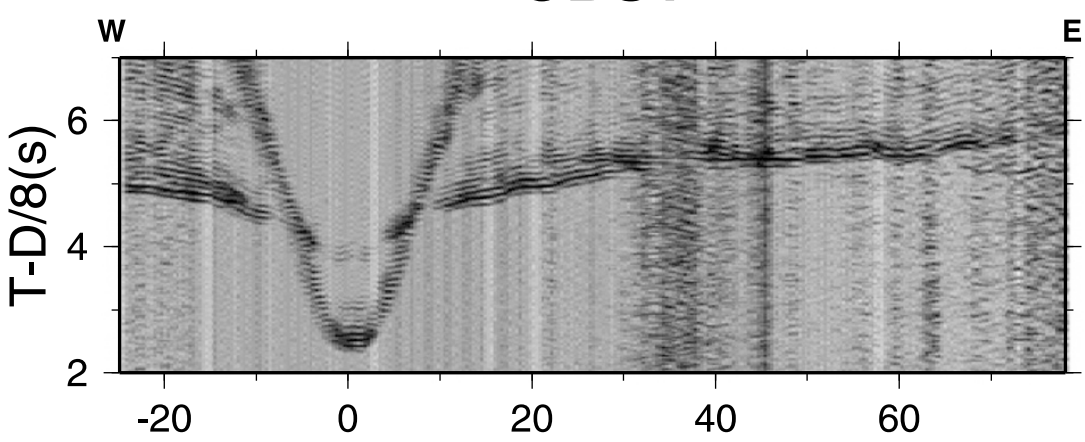

(b)

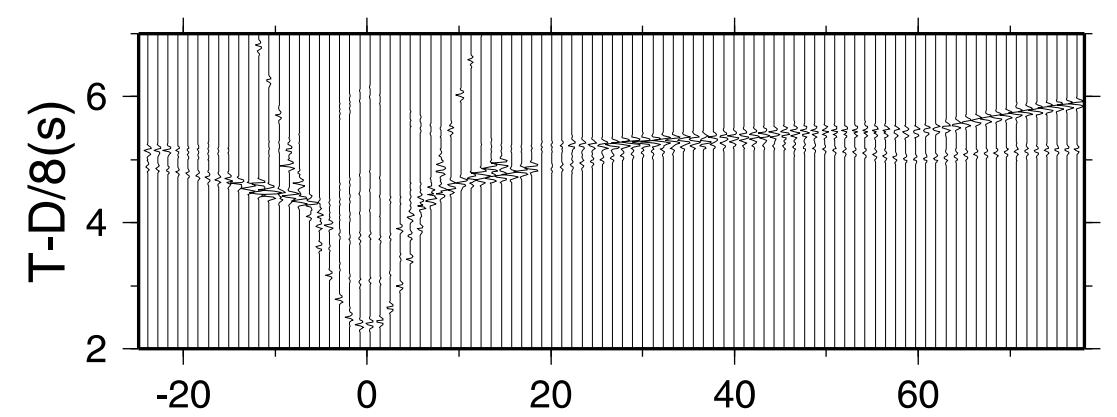

(c)

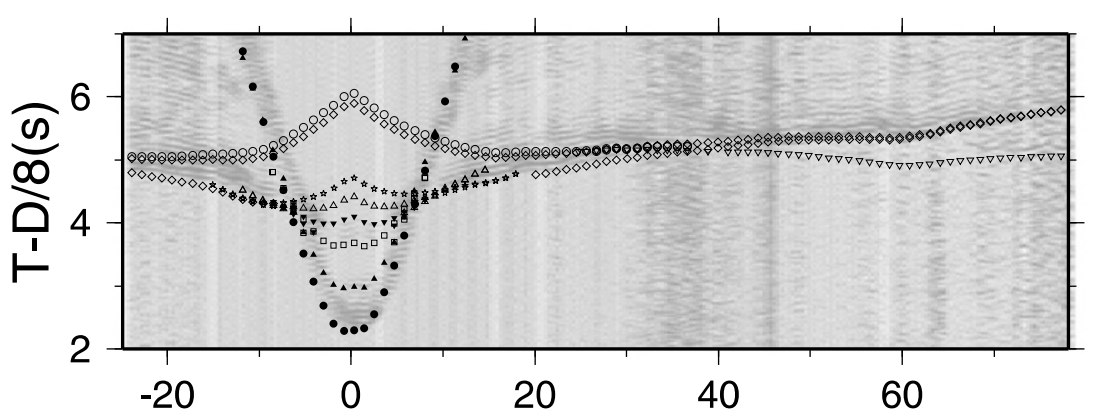

(d)

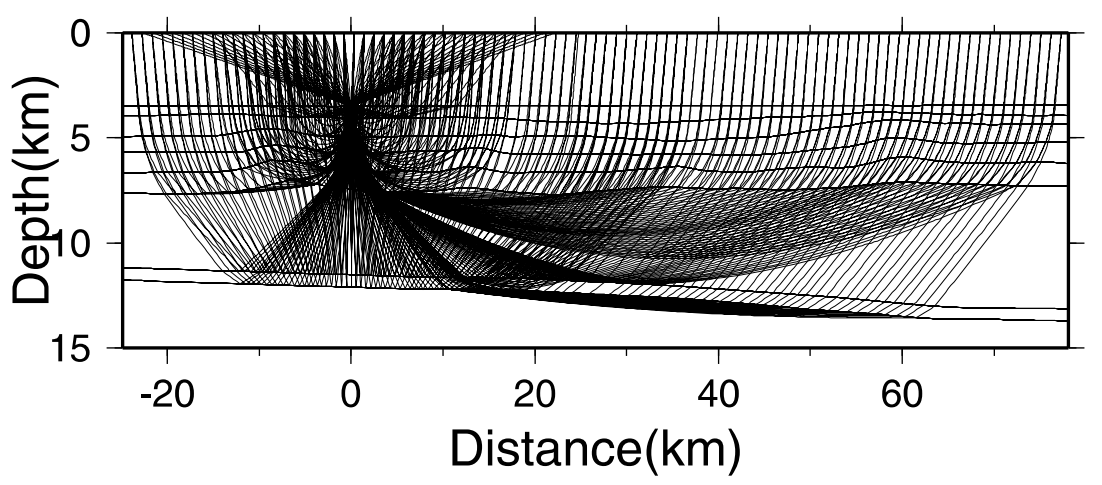

Fig. 2. Observed and synthetic seismograms for OBS1. (a): Record section for vertical component, high gain channel. Digital band-pass filtering is 5.0-15.0 Hz. Each trace is normalized by its maximum amplitude. (b): Synthetic seismograms estimated from the $P$-wave velocity model using the ray theory. (c): Calculated travel times for the model using the 2-D ray tracing method superimposed on (a). Solid circles indicate travel time of water waves. Solid triangles, open squares, solid inverted triangles, open triangles, open stars, open diamonds, open squares and open inverted triangles denote travel times of reflection and refraction waves through the first, second, third, fourth, fifth, sixth, seventh and eighth layer from the sea floor, respectively. (d): Ray path diagrams for OBS1. The vertical axes of (a), (b) and (c) are travel time reduced by $8 \mathrm{~km} / \mathrm{s}$. The vertical axis of (d) is the depth from the sea level. The horizontal axes are the offset distance in $\mathrm{km}$ between the OBS and shots.

tary layer consists of two units; the upper unit has a $P$-wave velocity of $1.7 \mathrm{~km} / \mathrm{s}$, and $P$-wave velocity of the lower unit is $2.2-2.7 \mathrm{~km} / \mathrm{s}$. Total thickness of the sedimentary layer is about $1.5 \mathrm{~km}$ beneath OBS1 and OBS2, and about $0.7 \mathrm{~km}$ beneath OBS3. Beneath the sedimentary layer, the upper part of the crust has three layers, which are 3.8-4.3, 4.75.1 and $5.9-6.2 \mathrm{~km} / \mathrm{s}$, respectively. Theoretical travel times from these layers in the velocity model are well explained to triplications and the observed seismograms (Fig. 6(b)). Total thickness of this part is about $2.5 \mathrm{~km}$ beneath OBS1 and 2 , and $2.9 \mathrm{~km}$ beneath OBS3. Underneath that part, the lower part of the crust, which has $P$-wave velocity of $6.8-$ $6.9 \mathrm{~km} / \mathrm{s}$, is $4.0-4.5 \mathrm{~km}$ thick below OBS1 and OBS2, and $5.6 \mathrm{~km}$ thick below OBS3. A transition zone with thickness 
(a)

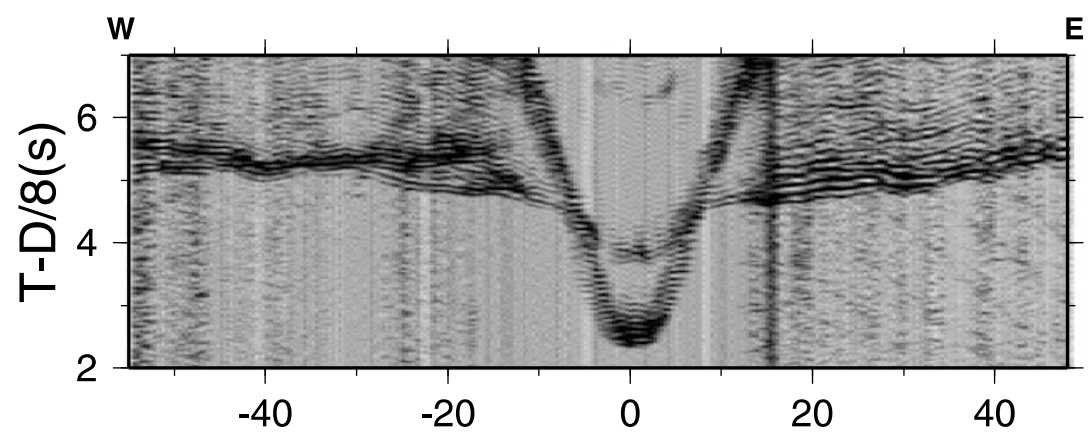

(b)

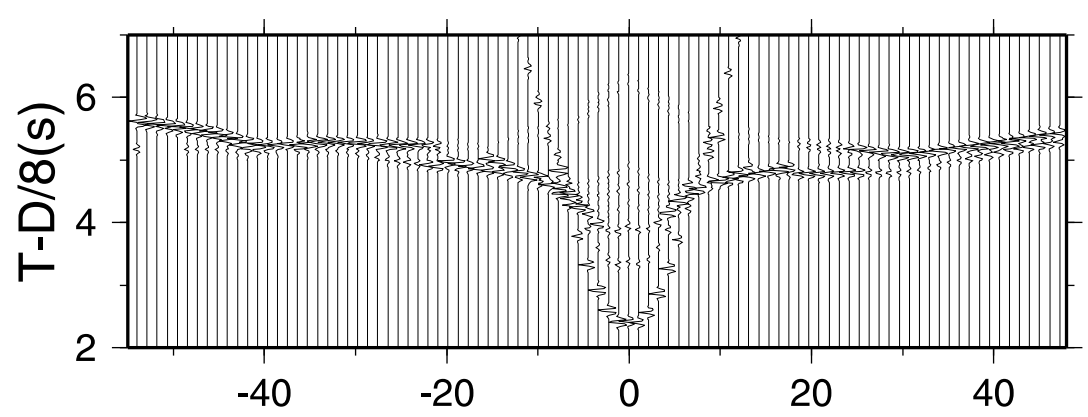

(c)

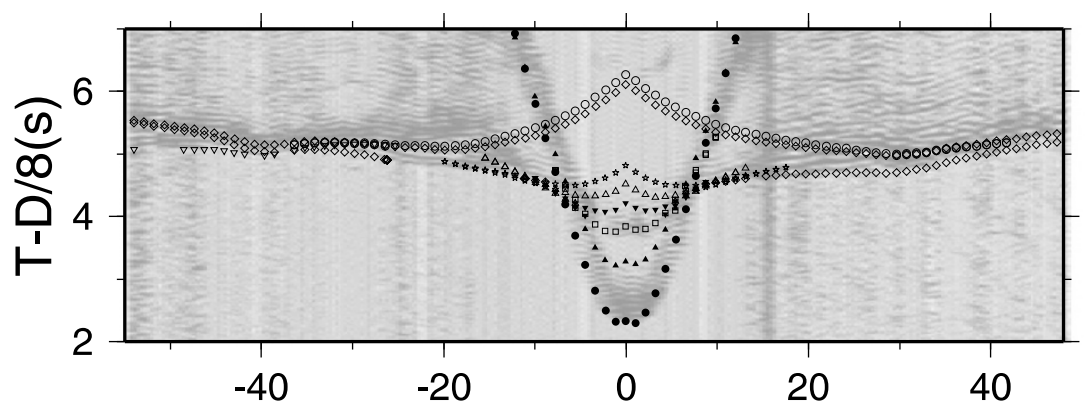

(d)

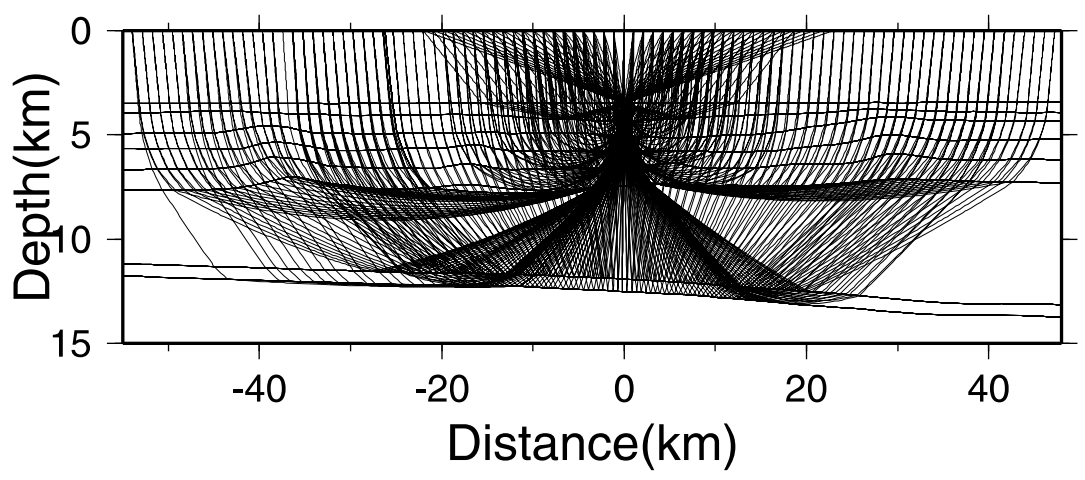

Fig. 3. Observed and synthetic seismograms for OBS2. See Fig. 2 for detailed explanation.

of about $0.6 \mathrm{~km}$ and $P$-wave velocity of approximately 7.5 $\mathrm{km} / \mathrm{s}$ is needed at the bottom of the crust to explain the relative amplitudes of first and later arrivals beyond the offset distances of $25-35 \mathrm{~km}$ (Fig. 8). And, the synthetic amplitudes from velocity model with this zone rather than those without this zone are well explained to the observed seismograms (Fig. 8). Uppermost mantle velocities are $8.1 \mathrm{~km} / \mathrm{s}$ beneath OBS1, $8.0 \mathrm{~km} / \mathrm{s}$ beneath OBS2 and $7.9 \mathrm{~km} / \mathrm{s}$ beneath OBS3, respectively. The total thickness of the crust, including the sedimentary layer, is about $9 \mathrm{~km}$ beneath OBS1 and OBS2, and about $10 \mathrm{~km}$ beneath OBS3.

\section{Discussion}

This study suggests that the northern part of the central Japan Basin has a minimum 9-km thick crust, including a $1.5-\mathrm{km}$ thick sedimentary layer. Figure 9 shows a comparison of the crustal velocity model of this study with those of 3 to $15 \mathrm{Ma}$ old oceanic crust in the Pacific Ocean (White et al., 1992). The thickness of the upper part of crust (3.8$4.3,4.7-5.1$ and $5.9-6.2 \mathrm{~km} / \mathrm{s})$ in this study is slightly thicker than that of oceanic layer 2 (White et al., 1992). The $P$-wave velocities of the upper part of crust, on the other hand, are slightly slower than that of a typical oceanic layer 2 (White 


\section{OBS3}

(a)

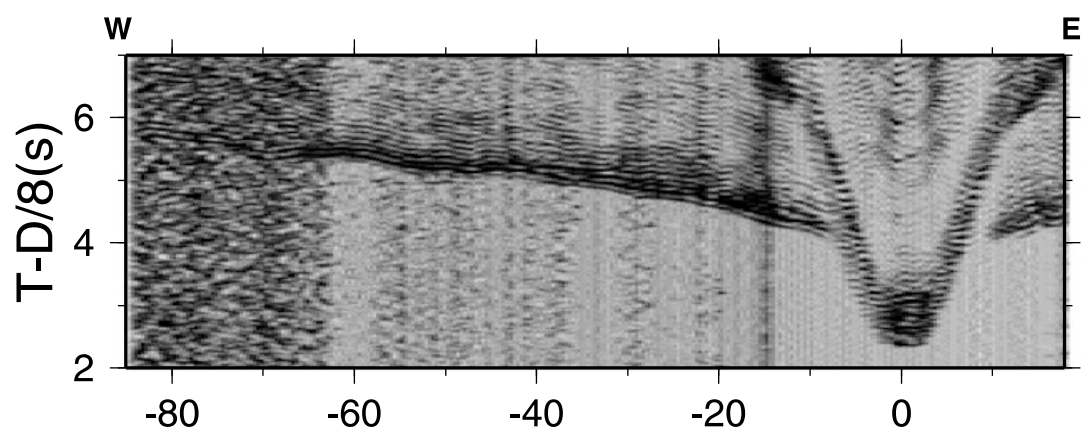

(b)

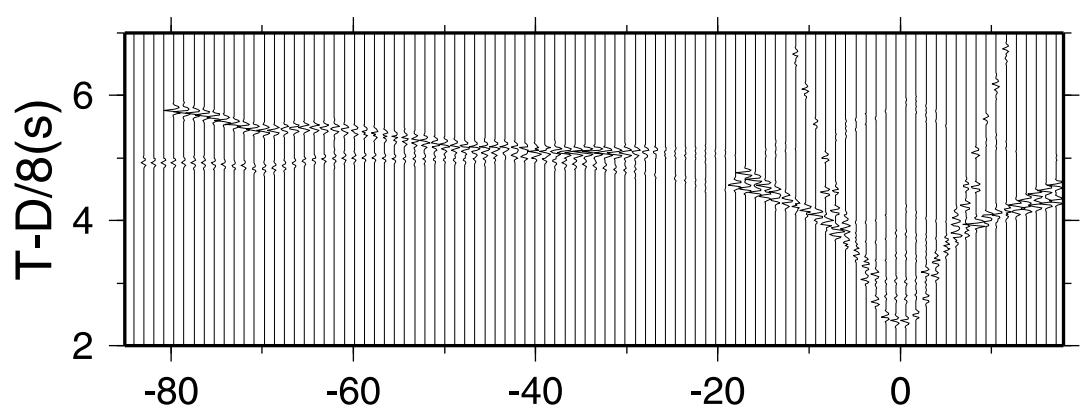

(c)

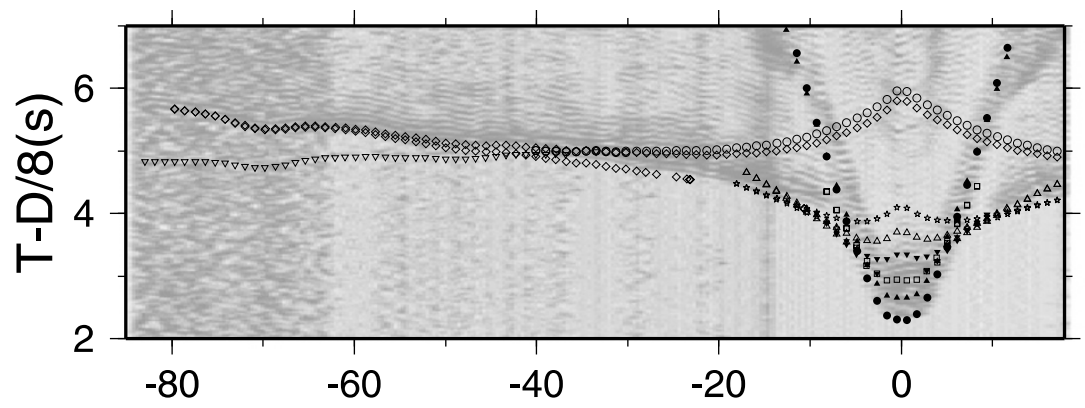

(d)

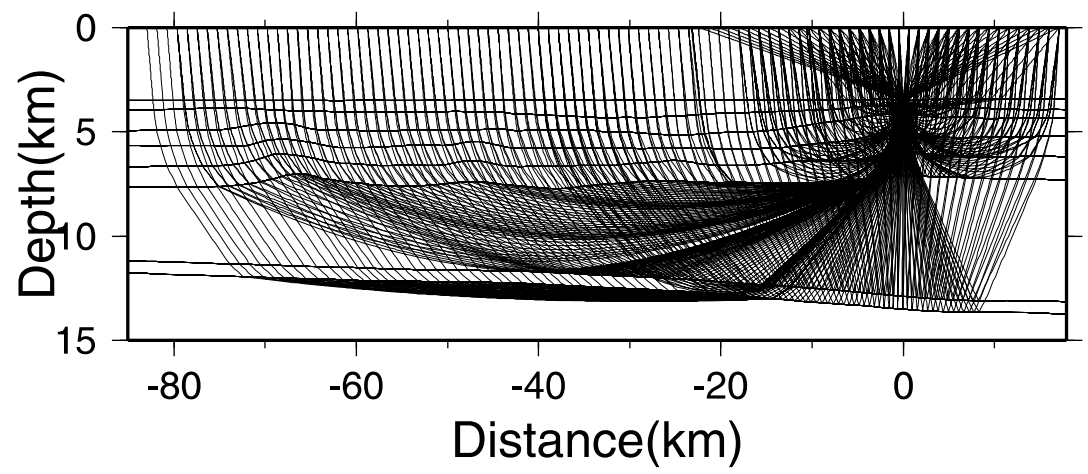

Fig. 4. Observed and synthetic seismograms for OBS3. See Fig. 2 for detailed explanation.

et al., 1992). However, the thickness and $P$-wave velocity of the lower part of crust $(6.8-6.9 \mathrm{~km} / \mathrm{s})$ is similar to that of a typical oceanic layer 3 (White et al., 1992) except beneath OBS3. The total crustal thickness is slightly thicker than that of a typical oceanic crust (White et al., 1992). As the result of the geomagnetic survey around this survey line, the linear geomagnetic anomaly, which is observed in oceanic basins formed by typical ocean floor spreading, is not confirmed (e.g., Isezaki, 1975; Nakasa and Kinoshita, 1994; Isezaki and Shevaldin, 1996). Therefore, these indicate that the crustal structure of the study area is not a typical oceanic crust and that the process of the formation of the study area differs from simple spreading at the oceanic ridges, even if the crust in the study area was created during the opening of the Japan Basin.

Anomalous thick crusts that are 9-12 km thick were found in spreading centers influenced by mantle plumes (White et al., 1992). In a case that a spreading center exists in a region of anomalously hot asthenospheric mantle near plumes, the crust is thicker than normal (White et al., 1992). Also, slightly thicker crust than that of a typical oceanic crust was found in the transition zone between the continental crust and 


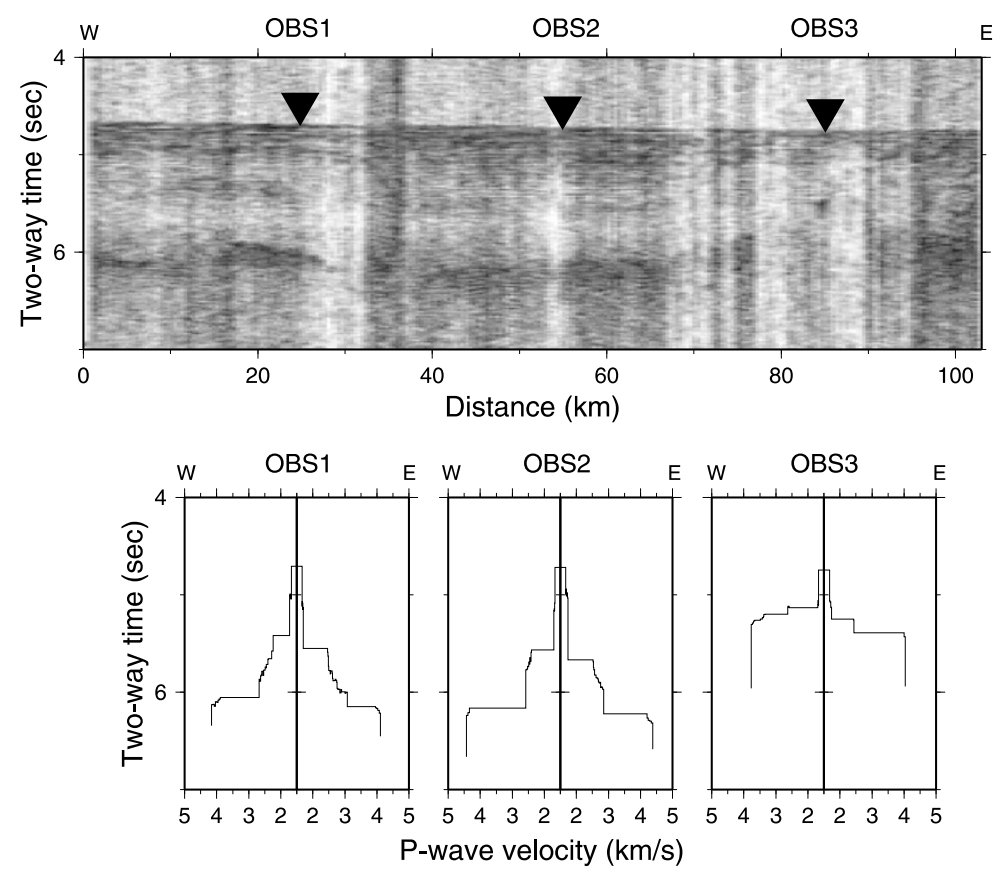

Fig. 5. (upper): The single channel seismic reflection (SCS) profile along the survey line. The vertical and horizontal axes are the two-way time from the sea surface and the distance from the western end of the survey line, respectively. (lower): The one-dimensional $P$-wave velocity structures just below each OBS. The vertical axes are the two-way time from the sea surface. The horizontal axes are $P$-wave velocities. The velocity structures were derived by $\tau$ - $p$ mapping and $\tau$-sum inversion to refraction data. Two velocity structures are the west and east side of each OBS, because $P$-wave velocity structures are obtained for the profile on either side of each OBS.

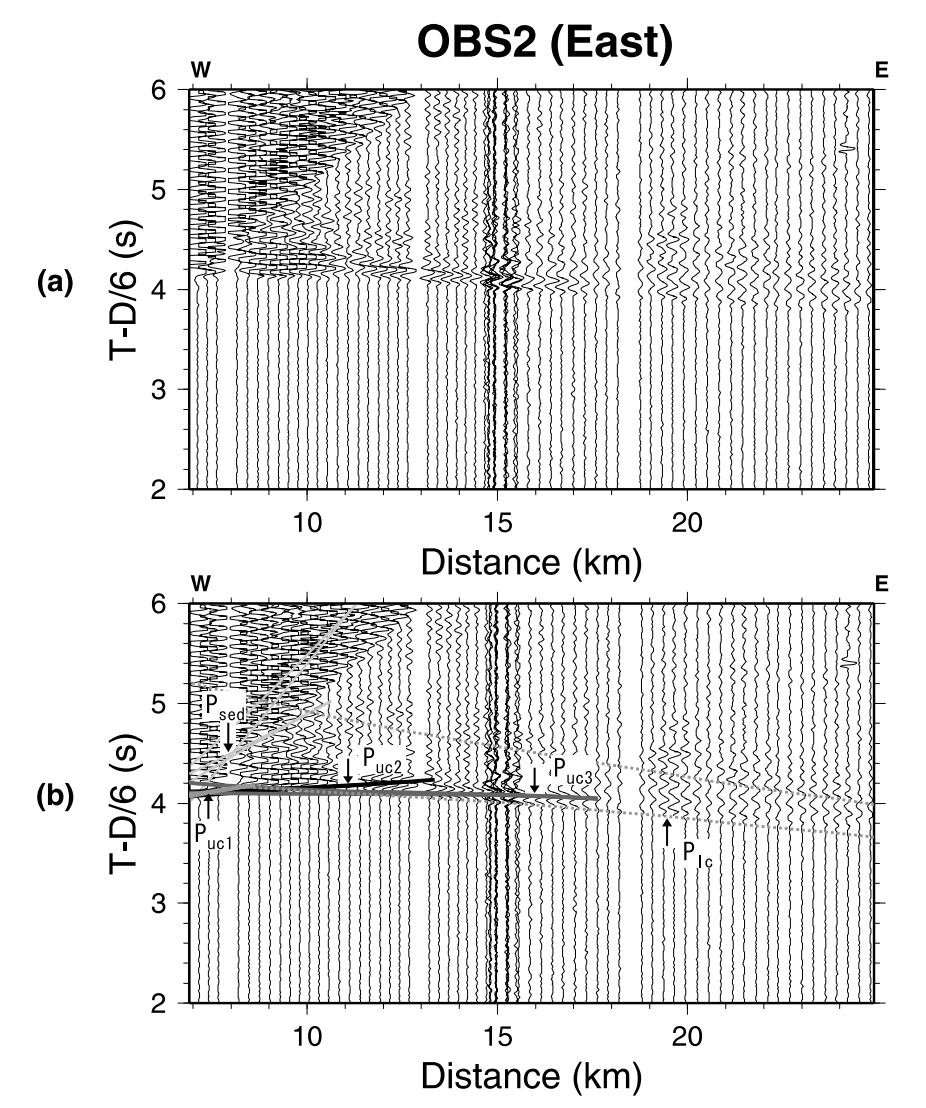

Fig. 6. OBS2 record and theoretical travel times calculated from the model using the 2-D ray tracing. (a): Record section of the east side of OBS2 for offsets from 6.9 to $25.0 \mathrm{~km}$. The OBS data is recorded on the vertical component. Digital band-pass filtering is 5.0-15.0 Hz. Each trace is applied a band-pass filter $(5.0-15.0 \mathrm{~Hz})$ and amplitude scaling of the square of the root of offsets. (b): Calculated travel time for the model using the 2-D ray tracing method superimposed on (a). Thick light gray, solid and thick dark gray lines indicate travel times of refraction and reflection waves through first $\left(3.8-4.3 \mathrm{~km} / \mathrm{s}\right.$ layer: $\left.P_{u c 1}\right)$, second $\left(4.7-5.1 \mathrm{~km} / \mathrm{s}\right.$ layer: $\left.P_{u c 2}\right)$ and third $\left(5.9-6.2 \mathrm{~km} / \mathrm{s}\right.$ layer: $\left.P_{u c 3}\right)$ layers in the upper part of the crust, respectively. Thin light gray and the gray dotted lines indicate travel times of refraction and reflection waves through the sedimentary layer $\left(P_{\text {sed }}\right)$ and lower part of the crust $\left(P_{l c}\right)$, respectively. The horizontal and vertical axes of (a) and (b) are the distance from OBS2 and travel time reduced by $6 \mathrm{~km} / \mathrm{s}$. 


\section{Central Japan Basin}

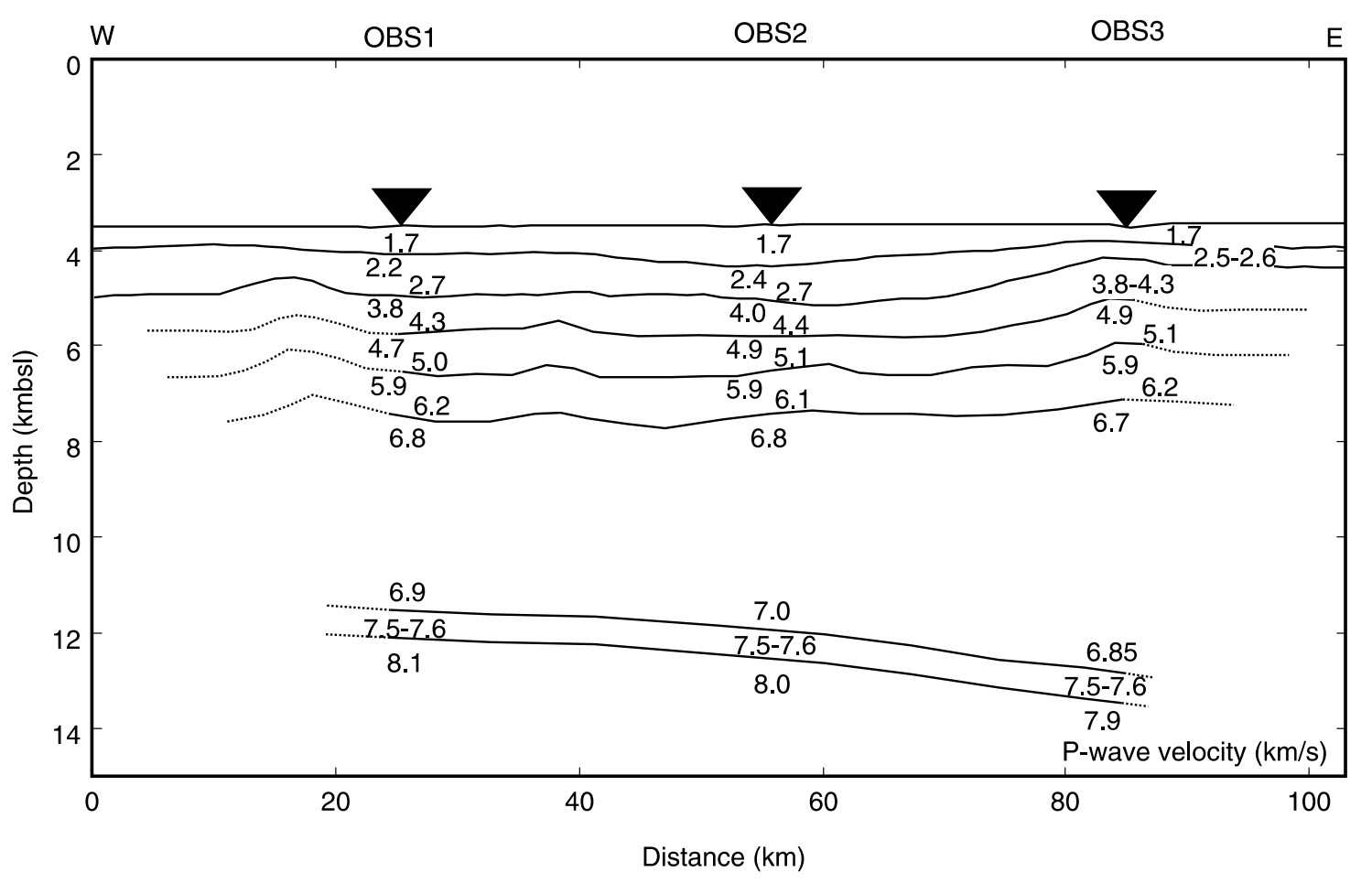

Fig. 7. $P$-wave velocity structure model in the northern part of the central Japan Basin estimated by the 2-D ray tracing method. The vertical axis is the depth from the sea surface. The horizontal axis is the distance from the western end of the survey line. Numerals are $P$-wave velocities in km/s. Inverted solid triangles indicate positions of the OBS. Solid lines denote the velocity boundaries with high reliability due to adequate ray coverage. The velocity interfaces in sedimentary layers are determined from the seismic reflection profile. Broken lines indicate the velocity boundaries estimated with inadequate ray coverage.

the oceanic crust as seen in passive margins (e.g., Whitmarsh et al., 1990). The continental crust may have been thinned to less than $1 / 5$ of its original thickness at non-volcanic margins, which means that the thickness of a thinned continental crust is comparable to that of the oceanic crust. The crustal thickness obtained from this study is similar both to that of the oceanic crust affected plumes and that of thinned continental crust. The crustal type proposed by Tamaki et al. (1992) suggests that the crustal type around this study area corresponds to the transition from the oceanic crust to the extended continental crust, though they didn't clearly define (Fig. 10).

In the case that the crustal type is the oceanic crust affected plumes such as around the Hatton Bank in the north Atlantic margin, the linear geomagnetic anomaly can be seen (e.g., Talwani and Eldholm, 1977) and the thick high velocity layer, namely with $P$-wave velocity greater than $7.0 \mathrm{~km} / \mathrm{s}$ may be thicker than about $5 \mathrm{~km}$, in the lower part of crust (e.g., Fowler et al., 1989). However, around this survey line, the clear linear geomagnetic anomaly has not been confirmed (e.g., Isezaki, 1975; Nakasa and Kinoshita, 1994; Isezaki and Shevaldin, 1996) moreover this high velocity layer does not exist in this result. This suggests that this crust in the study area may be the thinned continental crust rather than the oceanic crust affected by plumes.

In the northeastern Japan Basin, the velocity structure of the crust is consistent with those of typical oceanic crusts (Hirata et al., 1992) and linear magnetic anomalies are clearly observed in the area (e.g;, Isezaki and Uyeda, 1973; Isezaki, 1986; Seama and Isezaki, 1990). Therefore, the crust of the northeastern Japan Basin is interpreted to have been formed by sea floor spreading process. The crustal structure in the northern part of the central Japan Basin can be compared to that in the northeastern Japan Basin (Hirata et al., 1992) (Fig. 11). The upper part of the crust ( $V p<6.5$ $\mathrm{km} / \mathrm{s}$ ) is thicker in the central Japan Basin than that in the northeastern Japan. On the other hand, thickness of the lower part of the crust $(V p>6.5 \mathrm{~km} / \mathrm{s})$ of the central area is similar to that of the northeastern area. The crustal thickness excluding the sedimentary layer of the northern part of the central area is thicker than that of the northeastern area. The transition zone does not exist in the northeastern Japan Basin but in the northern part of central Japan Basin. And, the Moho deepens eastward in the northern part of the central area and deepens westward in the northeastern Japan Basin. From these differences between two areas, the formation process of the northern part of the central Japan Basin is inferred to be different from that of the northeastern Japan Basin.

\section{Conclusion}

This study presents a model of the $P$-wave velocity structure in the northern part of the central Japan Basin derived from OBS data using airgun shots. The sedimentary column consists of two layers $(1.7 \mathrm{~km} / \mathrm{s}$ and $2.2-2.7 \mathrm{~km} / \mathrm{s})$, whose thickness is about $1.5 \mathrm{~km}$ beneath OBS1 and OBS2, and is $0.7 \mathrm{~km}$ beneath OBS3. Beneath the sedimentary layer, the 
(a)
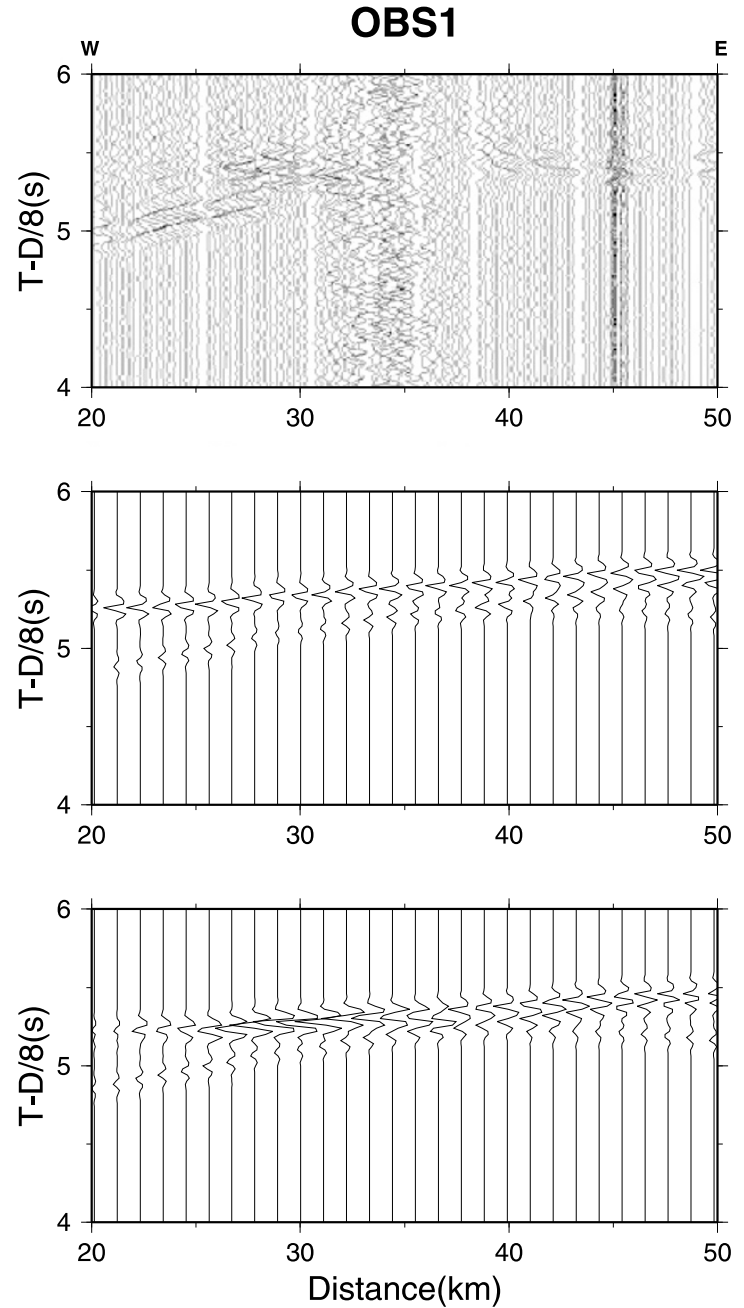

Fig. 8. Observed seismograms and comparison of synthetic amplitudes from different structure models for OBS1. (a): Record section for the vertical component. Band-pass filtering is $5.0-15.0 \mathrm{~Hz}$. (b): synthetic amplitude from the velocity structures without transition layer $(V p=7.5-7.6 \mathrm{~km} / \mathrm{s}$, thickness of about $0.6 \mathrm{~km}$ ). (c): synthetic amplitude from the velocity structures with transition layer.

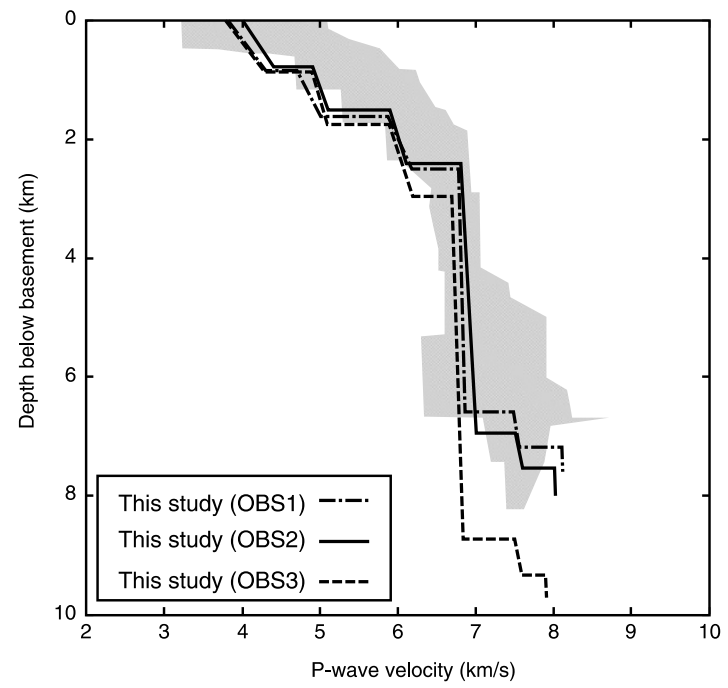

Structure of an oceanic crust

from Pacific Ocean with ages between

3 and 15 Ma compiled by White et al. (1992)

Fig. 9. Comparison the crustal structure of the northern part of the central Japan Basin (dash-dotted line beneath OBS1, solid line beneath OBS2 and dashed line beneath OBS3) and that of an oceanic crust in Pacific with ages between 3 and 15 Ma (shaded area) compiled by White et al. (1992). The Horizontal axis is the $P$-wave velocity in $\mathrm{km} / \mathrm{s}$ and vertical axis is the depth below the basement in $\mathrm{km}$. 


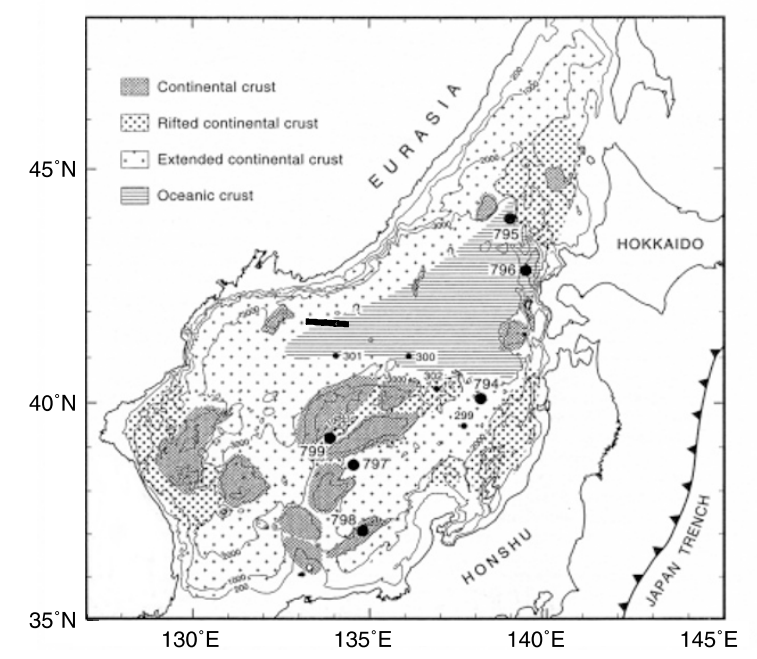

Fig. 10. The location of this survey line (thick line) and the discrimination of the crustal structure of the Japan Sea (after Tamaki et al., 1992).

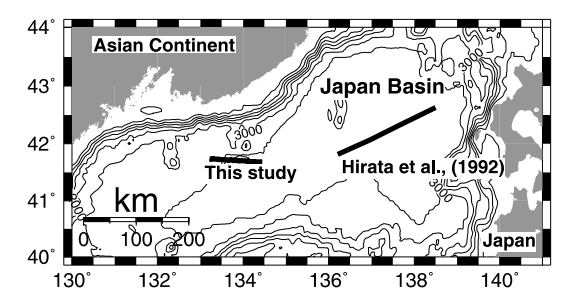

Central Japan Basin

Northeastern Japan Basin

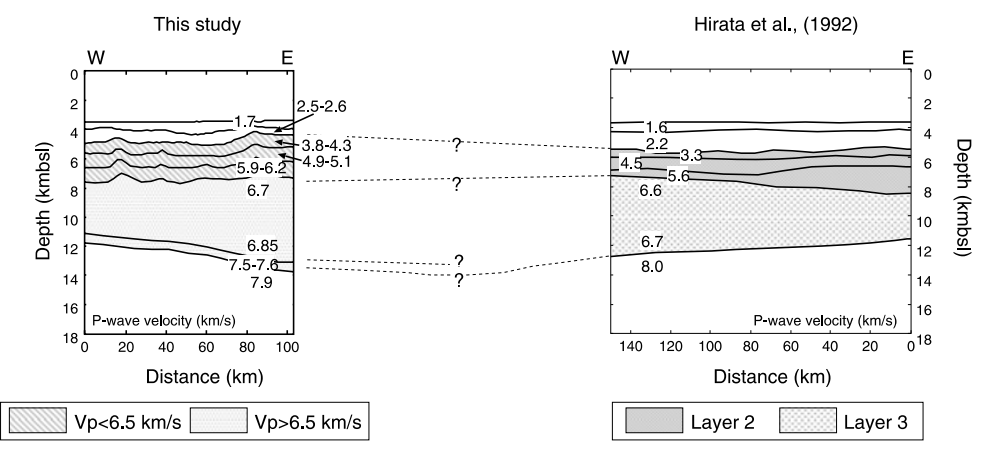

Fig. 11. Comparison of 2-D $P$-wave velocity structure between the northern part of the central Japan Basin and the northeastern Japan Basin (Hirata $e t$ al., 1992) (lower). The vertical axis is the depth below the sea level. The horizontal axis is the distance from the western end of survey line in the central and the eastern end of that in the northwestern. Positions of the profiles for 2-D velocity structures are shown (upper).

upper part of crust $(3.8-4.3,4.7-5.1$ and $5.9-6.2 \mathrm{~km} / \mathrm{s})$ has thickness of about $2.5 \mathrm{~km}$ in the central part of this profile. The lower part of the crust $(6.8-6.9 \mathrm{~km} / \mathrm{s})$ has thickness of about $4.2 \mathrm{~km}$ that thickens eastward. The crustal thickness, which is about $9 \mathrm{~km}$ including $1.5 \mathrm{~km}$ of the sedimentary layer in the central part, increases eastward. The crustal structure of the northern part of the central Japan Basin is slightly different from that of a typical oceanic crust, especially, thickness and velocities in the upper part of crust, which has less than $6.5 \mathrm{~km} / \mathrm{s}$ of the $P$-wave velocity, do not correspond to those of a typical oceanic crust. Also, it is unconfirmed the linear geomagnetic anomaly around this survey line. Although, the obtained $P$-wave velocity structure in the northern part of the central Japan Basin could be interpreted to be either both anomalous thick oceanic crust formed at spreading centers influenced by a mantle plume or thinned continental crust at ocean-continental boundaries in passive margins, this may be formed by thinning of a continental crust rather than by the melt of mantle plumes during the opening of the Japan Sea because of no confirming of the linear geomagnetic anomaly around this survey line. From the comparison of $P$-wave velocity structure and magnetic anomalies between the study area and the northeastern Japan Basin, the formation process of the northern part of the central Japan Basin is inferred not to be formed by typical ocean floor spreading. For these interpretations, it is considered to the process that the Japan Basin has formed complicatedly.

Acknowledgments. This experiment was conducted under the agreement of joint research on the Japan Basin between POI and Chiba University. We thank the captain, officers, crew and scientific members of the R/V Professor Gagarinsky. We gratefully acknowledge Dr. Char-Shine Liu and an anonymous reviewer for critical comments and suggestions. The figures and maps in this paper were made using the GMT graphic package (Wessel and Smith, 1998). 
This research is partly supported by the Grant-in-Aid for Scientific Research, number 08045022, from the Ministry of Education, Science, Culture and Sports of Japan.

\section{References}

Červený, V., I. A. Molotkov, and I. Pšenčik, Ray Method in Seismology, 215 pp, Univerzita Karlova, Prague, 1977.

Diebold, J. B. and P. L. Stoffa, The traveltime equation, $\tau-p$ mapping, and the inversion of common midpoint data, Geophysics, 46, 238-254, 1981.

Fowler, S. R., R. S. White, G. D. Spence, and G. K. Westbrook, The Hatton Bank continental margin-II. Deep structure from two-ship expanding spread seismic profiles, Geophys. J., 96, 295-309, 1989.

Hirata, N. and N. Shinjo, SEISOBS - modified version of SEIS83 for ocean bottom seismograms-, Zisin2 (J. Seismo. Soc. Jpn.), 39, 317-321, 1986 (in Japanese).

Hirata, N., H. Tokuyama, and T. W. Chung, An anomalously thick layering of the crust of the Yamato Basin, southeastern Sea of Japan: the final stage of back-arc spreading, Tectonophysics, 165, 303-314, 1989.

Hirata, N., B. Karp, T. Yamaguchi, T. Kanazawa, K. Suyehiro, J. Kasahara, H. Shiobara, M. Shinohara, and H. Kinoshita, Oceanic crust in the Japan Basin of the Japan Sea by the 1990 JAPAN-USSR Expedition, Geophys. Res. Lett., 19, 2027-2030, 1992.

Isezaki, N., Possible spreading centers in the Japan Sea, Marine Geophys. Res., 2, 265-277, 1975.

Isezaki, N., A magnetic anomaly map of the Japan Sea, J. Geomag. Geoelectr., 38, 403-410, 1986.

Isezaki, N. and Y. V. Shevaldin, Geomagnetic anomalies of the Japan Sea, in Geology and Geophysics of the Japan Sea, Japan-USSR Monograph Series 1, edited by N. Isezaki, I. I. Bersenev, K. Tamaki, B. Y. Karp, and E. P. Lelikov, pp. 41-47, Terrapub, 1996.

Isezaki, N. and S. Uyeda, Geomagnetic anomaly pattern of the Japan Sea, Marine Geophys. Res., 2, 51-59, 1973.

Kim, H. J., S. J. Han, G. H. Lee, and S. Huh, Seismic study of the Ulleung Basin crust and its implications for the opening of the East Sea (Japan Sea), Marine Geophys. Res., 20, 219-237, 1998.

Kurashimo, E., M. Shinohara, K. Suyehiro, J. Kasahara, and N. Hirata, Seismic evidence for stretched continental crust in the Japan Sea, Geophys. Res. Lett., 23, 3067-3070, 1996.

Ludwig, W. J., S. Murauchi, and R. E. Houtz, Sediments and structure of the Japan sea, Geol. Soc. Am. Bull., 86, 651-664, 1975.

Murauchi, S., Seismic crustal structure of the Japan Sea by controlled source experiment, Kagaku, 42, 367-375, 1972 (in Japanese).

Nakasa, Y. and H. Kinoshita, A supplement to magnetic anomaly of the Japan Basin, J. Geomag. Geoelectr., 46, 481-500, 1994.
Nishisaka, H., M. Shinohara, T. Sato, R. Hino, K. Mochizuki, and J. Kasahara, Crustal structure of the Yamato Basin and the margin of the northeastern Japan Sea using ocean bottom seismographs and controlled sources, Zisin2 (J. Seismo. Soc. Jpn.), 54, 365-379, 2001 (in Japanese with English abstract).

Nishizawa, A. and A. Asada, Deep crustal structure off Akita, eastern margin of the Japan Sea, deduced from ocean bottom seismographic measurements, Tectonophysics, 306, 199-216, 1999.

Sato, T., M. Shinohara, K. Suyehiro, B. Y. Karp, R. G. Kulinich, and N. Isezaki, Seismic velocity structure of Kita-Yamato Trough, Japan Sea revealed by ocean bottom seismometer and airgun survey, Zisin2 (J. Seismo. Soc. Jpn.), 53, 337-355, 2001 (in Japanese with English abstract).

Seama, N. and N. Isezaki, Sea-floor magnetization in the eastern part of the Japan Basin and its tectonic implications, Tectonophysics, 181, 285-297, 1990.

Shinohara, M., K. Suyehiro, S. Matsuda, and K. Ozawa, Digital recording ocean bottom seismometer using portable digital audio tape recorder, $J$. Japan Soc. Marine Surveys Technol., 5, 21-31, 1993 (in Japanese with English abstract).

Shinohara, M., N. Hirata, and N. Takahashi, High resolution velocity analysis of ocean bottom seismometer data by $\tau$-p method, Marine Geophys. Res., 16, 185-199 1994.

Talwani, M. and O. Eldholm, Evolution of the Norwegian-Greenland Sea, Geol. Soc. Am. Bull., 88, 969-999, 1977.

Tamaki, K., K. Suyehiro, J. Allan, J. C. Ingle, Jr., and K. A. Pisciotto, Tectonic synthesis and implications of Japan Sea ODP Drilling, Proc. ODP, Sci. Results, 127/128, edited by K. Tamaki, K. Suyehiro, J. Allan, M. McWilliams et al., pp. 1333-1348, Pt. 2 College Station, TX Ocean Drilling Program, 1992.

Wessel, P. and W. H. F. Smith, New, improved version of the Generic Mapping Tools released, EOS Trans. Am. Geophys. Union, 79, 579, 1998.

White, R. S., D. P. McKenzie, and R. K. O'Nions, Oceanic crustal thickness from seismic measurements and rare earth element inversions, J. Geophys. Res., 97, 19683-19715, 1992.

Whitmarsh, R. B., P. R. Miles, and A. Mauffret, The ocean-continent boundary off the western continental margin of Iberia I. Cruatal structure at 40³0', Geophys. J. Int., 103, 509-531, 1990.

Yoshii, T., Terrestrial heat flow and features of the upper mantle beneath the Pacific and Sea of Japan, J. Phys. Earth, 20, 271-285, 1972.

T. Sato (e-mail: tsato@jamstec.go.jp), M. Shinohara, B. Y. Karp, R. G. Kulinich, and N. Isezaki 